\title{
Top 10 Key Risk Factors of GZA Project Implementation Are Identified with Analytic Hierarchy Process
}

\author{
Jiangping Wan, Guangwei Pan \\ School of Business Administration, South China University of Technology, Guangzhou, China \\ Email: csipwan@scut.edu.cn, guangwei pan@foxmail.com
}

Received 28 April 2014; revised 4 June 2014; accepted 25 June 2014

Copyright (C) 2014 by authors and Scientific Research Publishing Inc.

This work is licensed under the Creative Commons Attribution International License (CC BY). http://creativecommons.org/licenses/by/4.0/

(c) (7) Open Access

\begin{abstract}
This paper has established the implementation process of government investment project-GZA with Wuli-Shili-Renli methodology. The risk factors of three levels in GZA project implementation process are identified with literature survey and expert investigation method. The risk factors evaluation model based on Analytic Hierarchy Process to evaluate the risk factors of GZA project is also established. The conclusion is that the most important primary risk factor is the forming target stage. The secondary risk factor is the decision risks. The top $\mathbf{1 0}$ key risk factors are in the following: scientificity, policy supporting, design quality, supervisory mechanism, drawing, costing, budget control, organization structure, personnel quality, democratic participation. The study attempts to facilitate designing the specific strategy to avoid risk in order to improve the GZA project implementation.
\end{abstract}

\section{Keywords}

GZA Project, Risk Factors, Analytic Hierarchy Process, Wuli-Shili-Renli Methodology

\section{Introduction}

Due to the characteristics and mode of operation of government investment projects, there has been a lot of chaos in the project, such as jerry-built project, misappropriation of construction funds and other phenomena. Risk management of government investment project has attracted the close attention from society. We urgently need to study risk factors from theory to practice in the process of government investment projects in order to prevent and control. GZA project is a super large infrastructure project build by Guangdong Province, Hang Kong and Macao with the first cooperation. The bridge that the project build crosses the Pearl River estuary area, 
which is a large sea-crossing passage linking Hongkong, Zhuhai and Macao. The project has characters of difficult construction, complex cooperation, sensitive environment of construction religion, high social attention etc. So it requires more effective risk management than the general projects, and the risk factor analysis is the basis of risk assessment as well as the subsequent risk management.

This paper is organized in the following: Section 2 is literature review, including Wuli-Shili-Renli (WSR) system methodology and project risk management. Section 3 is the research of key risk factors of GZA project implementation. Finally it is conclusions and acknowledgement.

\section{Literature Review}

\subsection{WSR System Methodology}

In 1994, on the basis of systematic research, China system scientist Professor Gu Jifa and Dr. Zhu Zhichang, combined with the research results of Tsien Hsueshen, Xu Guozhi, Song Jian, and proposed WSR that "WuliShili-Renli methodology" at HULL University, which was how effectively use the configuration to a system to solve the problem of methodology [1]. The general process of WSR is divided into seven steps: 1) Understanding intention; 2) Forming target; 3) Investing and analyzing; 4) Building strategy; 5) Choosing program; 6) Realizing construction; 7) Coordinating relations. In order to effectively solve the basic engineering "Wuli" problems, we must establish effective "Shili" system to manage and improve management efficiency, it must be people-oriented, build harmonious "people management" system to coordinate the "Renli" system [2].

\subsection{Project Risk Management}

Since the mid-1980s, various foreign risk management theories were applied to project management, especially the large civil engineering projects with the continuous development of our economy. For example, the Shanghai subway project in the implementation process has been successfully applied in project risk management method [3].

Zh. Y. Zhao, Y. Sh. Liu and H. Ch. Yang introduced the fault tree analysis method of the engineering reliability theory to the risk management of construction projects. The diagram deductive method was proposed to create the project risk fault tree. The project risk made identification and the risk factor quantification was approached. The minimal cut set method for detecting project's weakness was provided. Based on the binary system and the probability theory, the project successful degree was calculated and the minimizing of the costs to reduce the project sick was studied [4].

P. Guo and P. G. Shi proposed the grey clustering theory which could be used to obtain the index grey statistics and structure the project risk fuzzy subjection matrix and establish the comprehensive risk evaluation method of combing grey evaluation with fuzzy evaluation [5].

\section{Research of Key Risk Factors of GZA Project Implementation}

\subsection{Building Risk Factors Evaluation Model of GZA Project Implementation with AHP}

Based on WSR system methodology, we divide the working process of GZA project into 7 stages as 7 primary risk factors, including understanding intention, forming target, investing and analyzing, building strategy, choosing program, realizing construction, and coordinating relations. Through literature survey and expert investigation method, we refer to information department bulletin, some report of government investment project, industry association, the government policy, Chinese Journal Full-Text Database etc. 20 secondary risk factors and 82 category 3 risk factors of GZA project are recognized with comprehensive induction. We interview with management experts, government leaders, HD design company, GL Construction Company, HG supervision company, JC consulting firms and other senior experts. By repeatedly talking, constantly adjusting the revision, finally, we establish the indicator system of risk factors and build the Analytic Hierarchy Process (AHP) evaluation model, including 7 primary risk factors, 18 secondary risk factors and 53 category 3 risk factors (Figure 1).

The top goal A is the evaluated target: evaluation for GZA project implementation risk factors. The second criterion layer is as the primary risk factor indicators. The third criterion layer is as the secondary risk factor indicators. The fourth layer is category 3 risk factor indicators, which is the concrete manifestation of primary risk factors in GZA project implementation process. 


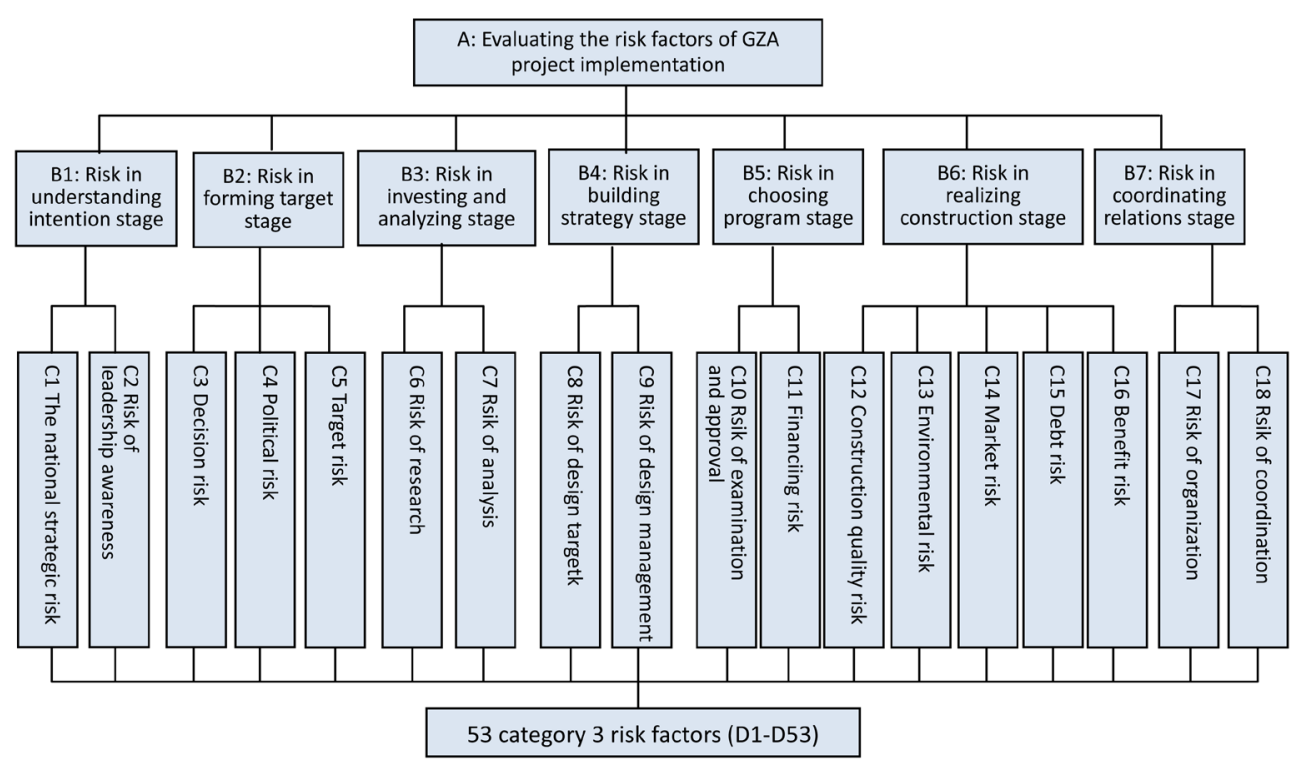

Figure 1. Evaluation model for GZA project implementation risk factors. D1-National development strategy; D2-National macro-control; D3-Government's intention; D4-Blind investment; D5-scienticify; D6-Democratic participation; D7-Supervision mechanism; D8-Cadres' rent-seeking behavior; D9-Policy supporting; D10Government's administrative efficiency; D11-General framework; D12-Necessity; D13-Feasibility; D14-Object; and content D15-Statistical information; D16-Data analysis; D17-Data prediction; D18-Time; D19-Costing; D20-Design quality; D21-Subcontracting; D22-alteration; D23-Policy; D24-Approval process; D25-Approval supervision; D26-Financing scale; D27-Financial market; D28-Approval Management; D29-Legal system; D30-Drawing; D31-Construction technology; D32-Personnel quality; D33-Building Materials; D34-Policy; D35-Macro-economic; D36-Force majeure; D37-Market price; D38-Market information; D39-Into market timing; D40-Market demand outlook; D41-Lending rates; D42-Budget control; D43-Investment; D44-Debt control mechanism; D45-Market acceptance; D46-Operating expenses; D47-Financial Support; D48-Organization structure; D49-Organizational personnel; D50-Resources and environment; D51-Organizational processes; D52-External coordination; D53-Internal coordination.

\subsection{Weight Calculation and Consistency Check on Risk Factors of GZA Project Implementation}

8 experts are invited to judge and give scores to the importance of each indicator of criterion relative to the higher criterion layer based on the 1 - 9 scale of AHP method. Thereby judgment matrixes is established, and consistency check on is taken.

We deal with the sores from 8 experts, the original data of judgment matrixes of each layer is got. We get the relative weight of each risk factor in risk factors evaluation model through calculating. Judgment matrixes and calculation results are illustrated in Tables 1-3.

In the view of the calculation results, we can see the C.R. values of all judgment matrixes are less than 0.1. Therefore, all judgment matrixes pass the consistency check and the results are proved reliable. Based on the relative weight of each layer of risk factors, calculated the synthetic weights of various risk factors (Table 4). Performing a consistency test on total sorts by the Yaahp software, random consistency ratio C.R. of total sorts at all levels is less than 0.1 , so the results of total sorts at all levels are satisfactory consistency, the evaluation result is acceptable.

It can be drawn from the results: the most important primary risk factor is the forming target stage, and the secondary risk factor is the decision risks. The top 10 key risk factors are as follows: scientificity, policy supporting, design quality, supervisory mechanism, drawing, costing, budget control, organization structure, personnel quality, and democratic participation.

\section{Conclusions}

The AHP is applied to establish the risk factors evaluation model for the project GZA implementation. The re- 
Table 1. A-B judgment matrix and weights.

\begin{tabular}{cccccccccc}
\hline A & B1 & B2 & B3 & B4 & B5 & B6 & B7 & Wi & \\
B1 & 1 & $1 / 9$ & $1 / 2$ & $1 / 6$ & $1 / 3$ & $1 / 7$ & $1 / 4$ & 0.0271 & \\
B2 & 9 & 1 & 7 & 3 & 5 & 2 & 4 & 0.3570 & \\
B3 & 2 & $1 / 7$ & 1 & $1 / 4$ & $1 / 2$ & $1 / 5$ & $1 / 3$ & 0.0421 & C.R. $=0.0249$ \\
B4 & 6 & $1 / 3$ & 4 & 1 & 4 & $1 / 2$ & 2 & 0.1636 & $\lambda_{\max }=7.2032$ \\
B5 & 3 & $1 / 5$ & 2 & $1 / 4$ & 1 & $1 / 5$ & $1 / 2$ & 0.0604 & \\
B6 & 7 & $1 / 2$ & 5 & 2 & 5 & 1 & 4 & 0.2541 & \\
B7 & 4 & $1 / 4$ & 3 & $1 / 2$ & 2 & $1 / 4$ & 1 & 0.0957 & \\
\hline
\end{tabular}

Table 2. B-C judgment matrix and weights.

\begin{tabular}{|c|c|c|c|c|c|c|c|}
\hline B1 & C1 & C2 & & & & Wi & \multirow{3}{*}{$\begin{array}{c}\text { C.R. }=0.0000 \\
\lambda_{\max }=2.0000 \\
\text { For the weight of A: } 0.0267\end{array}$} \\
\hline C1 & 1 & 2 & & & & 0.6667 & \\
\hline C2 & $1 / 2$ & 1 & & & & 0.3333 & \\
\hline B2 & C3 & C4 & C5 & & & Wi & \multirow{4}{*}{$\begin{array}{c}\text { C.R. }=0.0089 \\
\lambda_{\max }=3.0092 \\
\text { For the weight of A: } 0.03546\end{array}$} \\
\hline C3 & 1 & 2 & 3 & & & 0.5390 & \\
\hline C4 & $1 / 2$ & 1 & 2 & & & 0.2973 & \\
\hline C5 & $1 / 3$ & $1 / 2$ & 1 & & & 0.1638 & \\
\hline B3 & C6 & C7 & & & & Wi & \multirow{3}{*}{$\begin{array}{c}\text { C.R. }=0.0000 \\
\lambda_{\max }=2.0000 \\
\text { For the weight of A: } 0.0429\end{array}$} \\
\hline C6 & 1 & 2 & & & & 0.6667 & \\
\hline C7 & $1 / 2$ & 1 & & & & 0.3333 & \\
\hline B4 & C8 & C9 & & & & $\mathrm{Wi}$ & \multirow{3}{*}{$\begin{array}{c}\text { C.R. }=0.0000 \\
\lambda_{\max }=2.0000 \\
\text { For the weight of A: } 0.1632\end{array}$} \\
\hline C8 & 1 & 3 & & & & 0.7500 & \\
\hline C9 & $1 / 3$ & 1 & & & & 0.2500 & \\
\hline B5 & C10 & C11 & & & & Wi & \multirow{3}{*}{$\begin{array}{c}\text { C.R. }=0.0629 \\
\lambda_{\max }=2.0000 \\
\text { For the weight of A: } 0.0629\end{array}$} \\
\hline C10 & 1 & 3 & & & & 0.7500 & \\
\hline C11 & $1 / 3$ & 1 & & & & 0.2500 & \\
\hline B6 & C12 & C13 & C14 & C15 & C16 & Wi & \multirow{6}{*}{$\begin{array}{c}\text { C.R. }=0.0109 \\
\lambda_{\max }=5.0487 \\
\text { For the weight of A: } 0.2516\end{array}$} \\
\hline C12 & 1 & 4 & 6 & 2 & 7 & 0.4639 & \\
\hline C13 & $1 / 4$ & 1 & 2 & $1 / 2$ & 3 & 0.1365 & \\
\hline C14 & $1 / 6$ & $1 \backslash 2$ & 1 & $1 / 4$ & 2 & 0.0776 & \\
\hline C15 & $1 / 2$ & 2 & 4 & 1 & 6 & 0.2731 & \\
\hline C16 & $1 / 7$ & $1 / 3$ & $1 / 2$ & $1 / 6$ & 1 & 0.0488 & \\
\hline B7 & C17 & C18 & & & & Wi & \multirow{3}{*}{$\begin{array}{c}\text { C.R. }=0.0000 \\
\lambda_{\max }=2.0000 \\
\text { For the weight of A: } 0.0971\end{array}$} \\
\hline C17 & 1 & 2 & & & & 0.6667 & \\
\hline C18 & $1 / 2$ & 1 & & & & 0.3333 & \\
\hline
\end{tabular}


Table 3. C-D judgment matrix and weights.

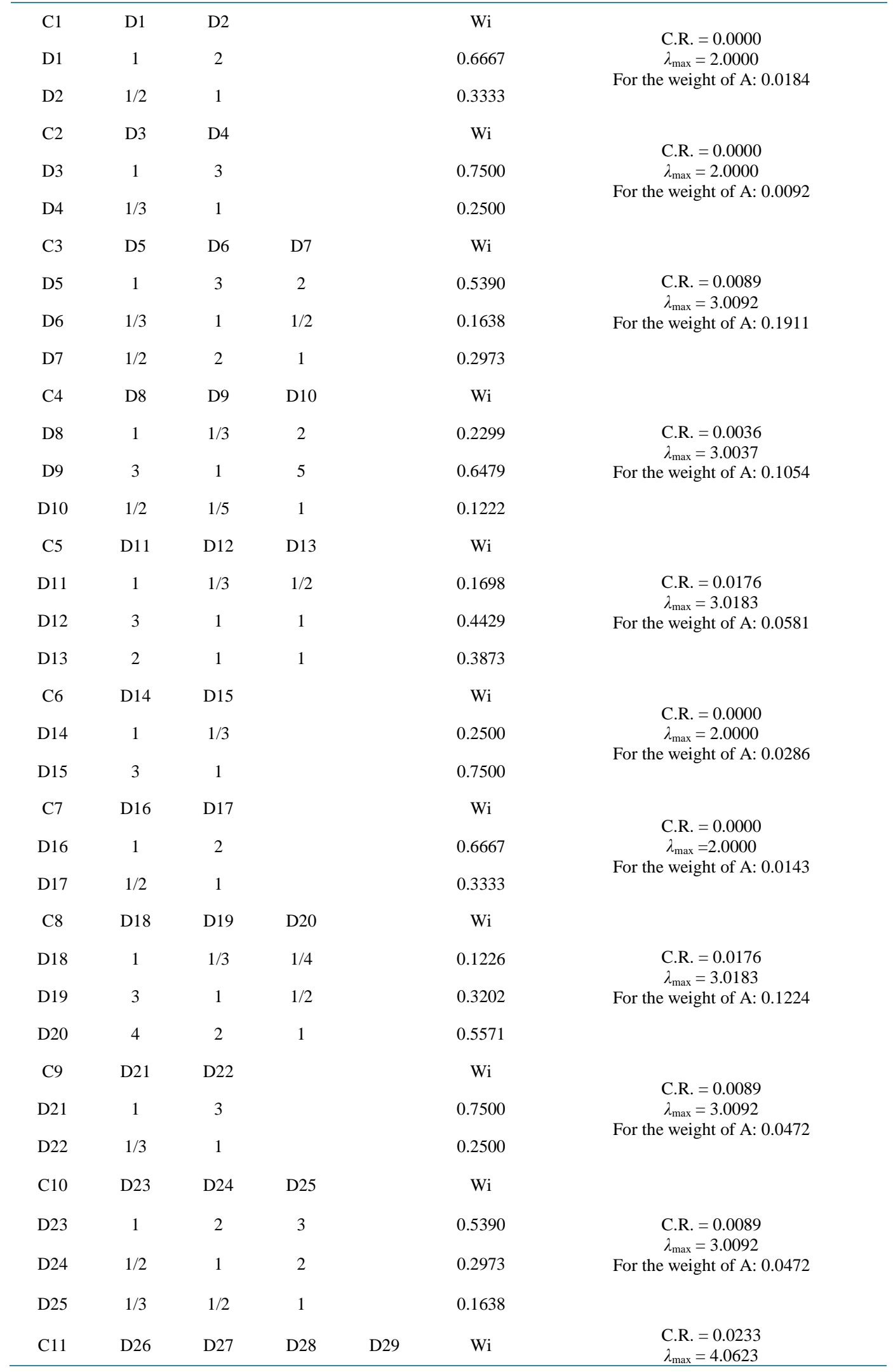




\section{Continued}

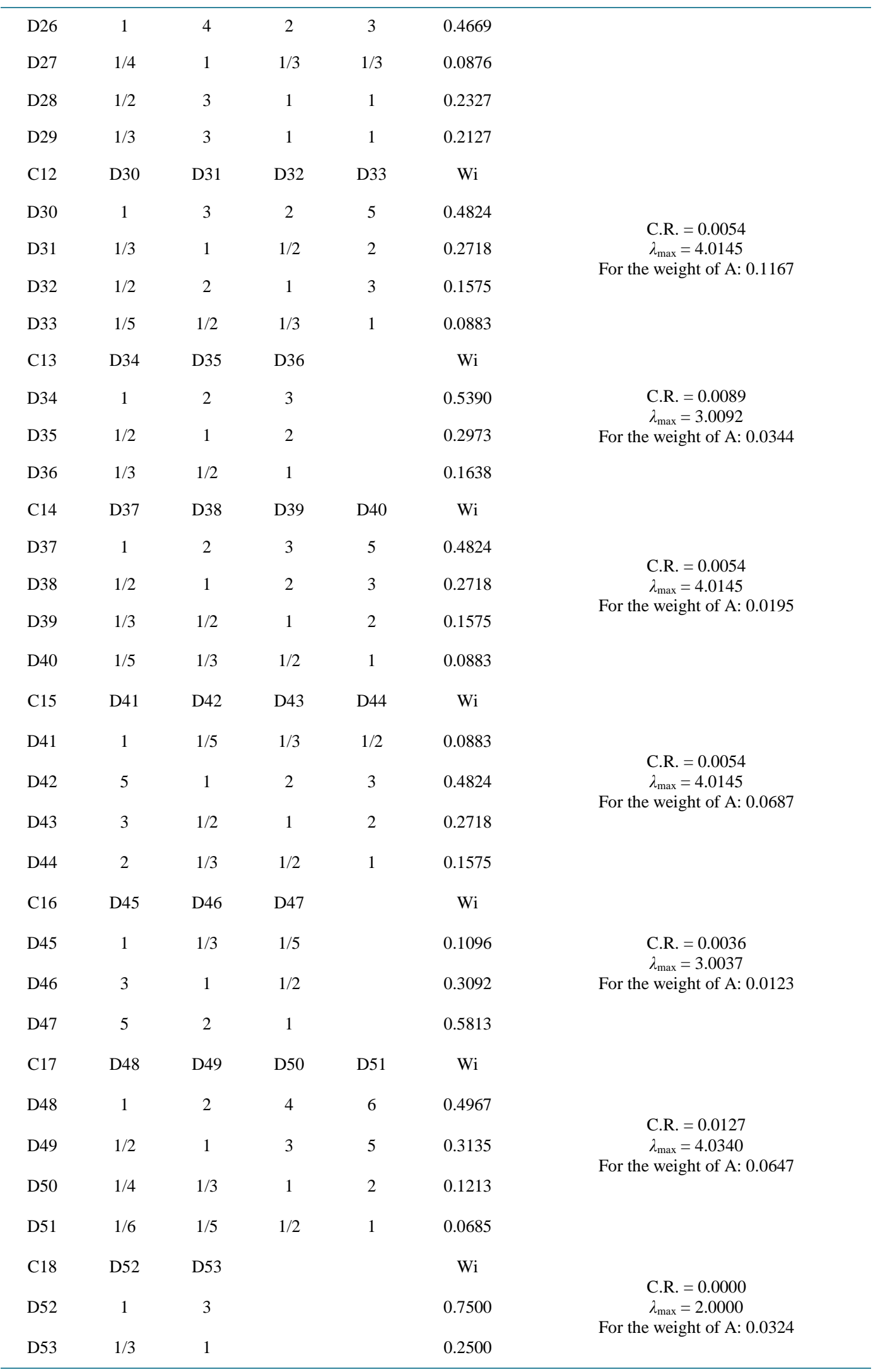


Table 4. The weight of risk factors.

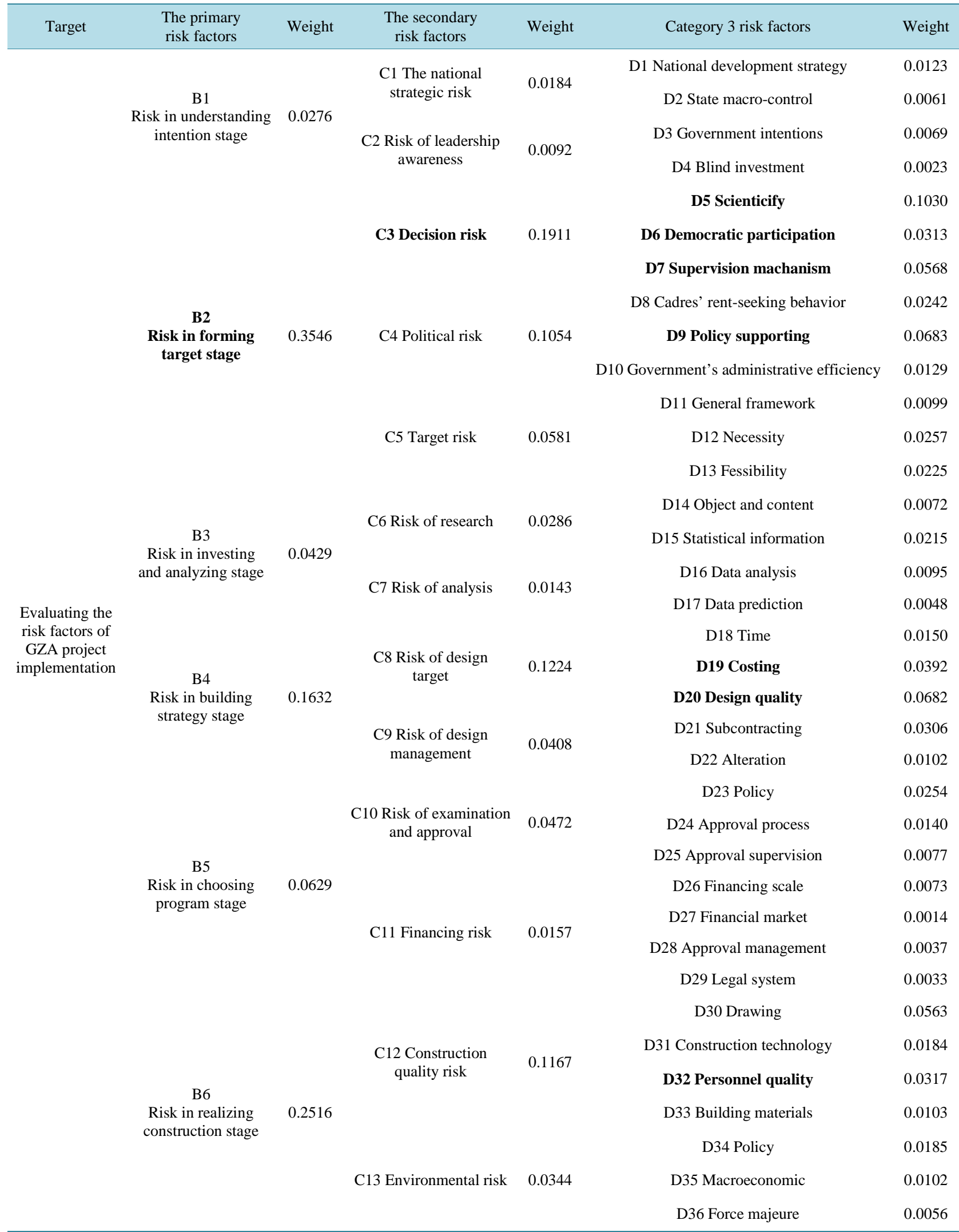


B7

Risk in coordinating $\quad 0.0971$ relations stage

\begin{tabular}{cccc} 
& & D37 Market price & 0.0094 \\
C14 Market risk & 0.0195 & D38 Market information & 0.0053 \\
& & D39 Into market timing & 0.0031 \\
& & D40 Market demand & 0.0017 \\
C15 Debt risk & 0.0687 & D41 Lending rates & 0.0061 \\
& & D42 Budget control & 0.0332 \\
& & D43 Investment & 0.0187 \\
C16 Benefit risk & 0.0123 & D44 Debt control mechanism & 0.0108 \\
& & D45 Market acceptance & 0.0013 \\
& & D46 Operating expenses & 0.0038 \\
C17 Risk of organization & 0.0647 & D47 Financial support & 0.0071 \\
& & D48 Organization structure & 0.0322 \\
& & D49 Organizational personnel & 0.0203 \\
& & D50 Resources and environment & 0.0079 \\
& & D51 Organizational processes & 0.0044 \\
& 0.0324 & D52 External coordination & 0.0243 \\
& & D53 Internal coordination & 0.0081 \\
\hline
\end{tabular}

sults are in the following: Currently the most important primary risk factors of GZA project implementation is in the forming target stage, which is consistent with the current situation of government investment projects difficult approval. In the secondary risk factors, decision risk is the most important. For government investment projects, the decisions on the phase of project approval have the most significant impact for the entire project. In category 3 risk factors the top 10 key risk factors are scientificity (D5, 0.1030), policy supporting (D9, 0.0683), design quality (D20, 0.0682), supervisory mechanism (D7, 0.0568), drawing (D30, 0.0563), costing (D19, 0.0392), budget control (D42, 0.0332), organization structure (D48, 0.0322), personnel quality (D32, 0.0317), democratic participation (D6, 0.0313). The top 10 risk factors focus on the forming target stage, realizing construction stage and building strategy stage. Therefore, GZA projects need to strengthen risk awareness in the three stages, take the rationalization of management measures.

In the future, we will apply the interpretive structural model to analyze the 10 key risk factors to identify the structure relationship between risk factors and the root of the risk factors in order to design the specific strategy to avoid risk and improve GZA project implementation.

\section{Acknowledgements}

Thanks for helpful discussion with Mr. Jing Xia, and Mr. Guoping Zhang etc.

\section{References}

[1] Gu, J.F. and Gao, F. (1998) To See Wuli-Shili-Renli Systems Approach from the View of Management Science. Systems Engineering Theory and Practice, 18, 1-5.

[2] Sheng, Zh.H., You, Q.Zh. and Li, Q. (2008) Methodology and Method of Large Scale Complex Engineering Management: Meta-Synthesis Management. Science \& Technology Progress and Policy, 25, 193-197.

[3] 233 Network School (2008) The Classification and Characteristics of Engineering Project Risk Management and Countermeasures. http://www.233.com/jzs1/xmgl/fudao/20080922/085417974.html

[4] Zhao, Zh.Y., Liu, Y.Sh. and Yang, H.Ch. (2002) Application of Fault Tree Analyzing Method to Risk Management of a Construction Project. Modern Electric Power, 19, 95-99.

[5] Guo, P. and Shi, P.G. (2005) Research on Fuzzy-Grey Comprehensive Evaluation Method of Project Risk. Journal of Xi'an University of Technology, 21, 106-109. 
Scientific Research Publishing (SCIRP) is one of the largest Open Access journal publishers. It is currently publishing more than 200 open access, online, peer-reviewed journals covering a wide range of academic disciplines. SCIRP serves the worldwide academic communities and contributes to the progress and application of science with its publication.

Other selected journals from SCIRP are listed as below. Submit your manuscript to us via either submit@scirp.org or Online Submission Portal.
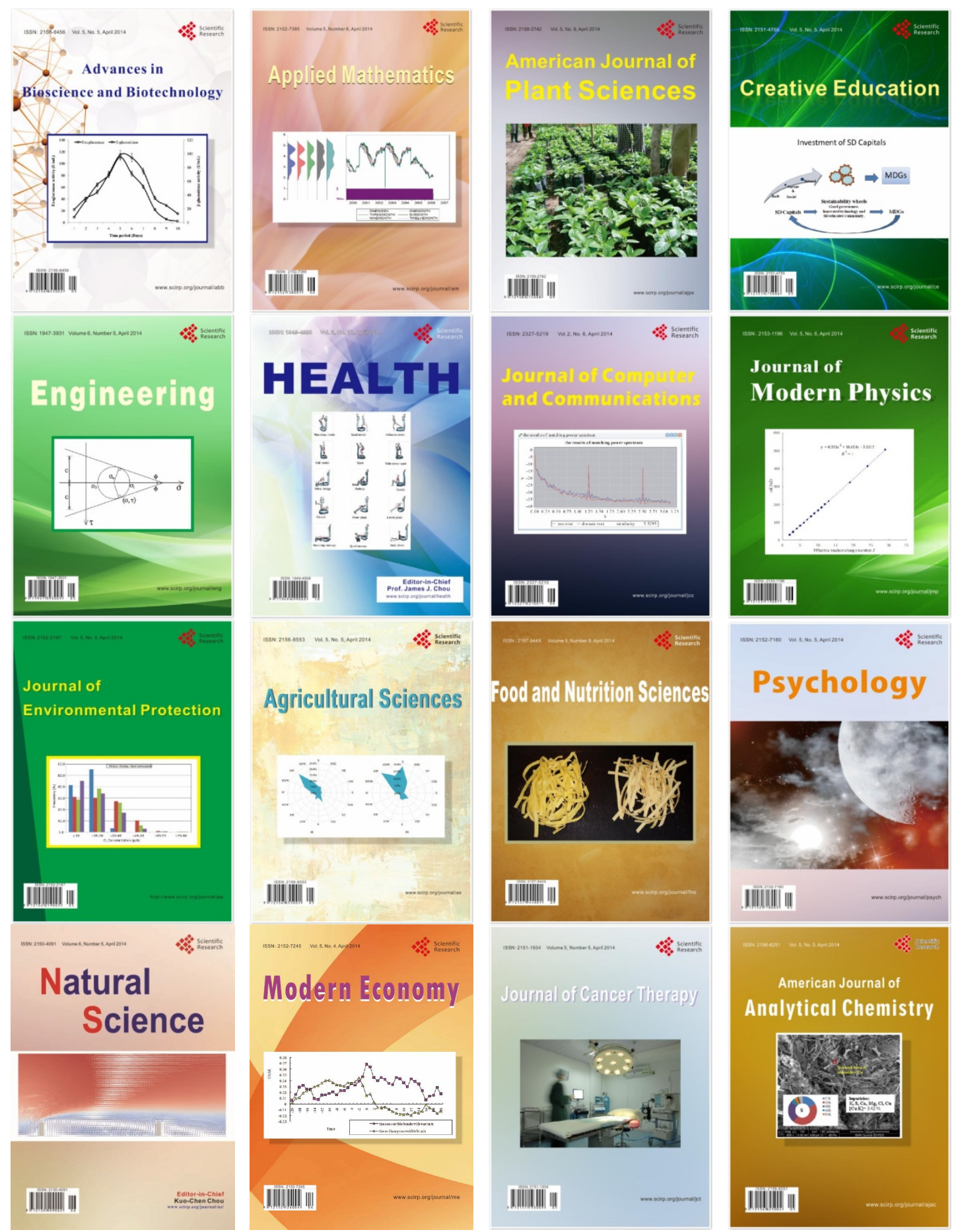